\title{
Article \\ Mathematical Modeling of Integral Characteristics of Repair Process under Maintenance Contracts
}

\author{
Nataša Kontrec ${ }^{1, *}++_{\mathbb{D}}$, Jelena Vujaković ${ }^{1,+} \mathbb{D}$, Marina Tošić ${ }^{1,+} \mathbb{D}$, Stefan Panić ${ }^{2,+} \mathbb{D}$ and Biljana Panić $3,+\mathbb{D}$ \\ 1 Department of Mathematics, Faculty of Sciences and Mathematics, University of Priština in Kosovska \\ Mitrovica, Lole Ribara 29, 38220 Kosovska Mitrovica, Serbia; jelena.vujakovic@pr.ac.rs (J.V.); \\ marina.tosic@pr.ac.rs (M.T.) \\ 2 Department of Informatics, Faculty of Sciences and Mathematics, University of Priština in Kosovska \\ Mitrovica, Lole Ribara 29, 38220 Kosovska Mitrovica, Serbia; stefan.panic@pr.ac.rs \\ 3 Department of Operation Research and Statistics, Faculty of Organizational Sciences, University of Belgrade, \\ Jove Ilica 154, 11000 Belgrade, Serbia; biljana.panic@fon.bg.ac.rs \\ * Correspondence: natasa.kontrec@pr.ac.rs \\ + These authors contributed equally to this work.
}

\section{check for} updates

Citation: Kontrec, N.; Vujaković, J.; Tošić, M.; Panić, S.; Panić, B. Mathematical Modeling of Integral Characteristics of Repair Process under Maintenance Contracts. Symmetry 2021, 13, 2360. https:// doi.org/10.3390/sym13122360

Academic Editors: Magdalena Machno, Paul Kainen, Teresa Gajewska, Andrzej Matras, Maciej Szkoda and Guangdong Tian

Received: 31 October 2021

Accepted: 29 November 2021

Published: 8 December 2021

Publisher's Note: MDPI stays neutral with regard to jurisdictional claims in published maps and institutional affiliations.

Copyright: (c) 2021 by the authors. Licensee MDPI, Basel, Switzerland. This article is an open access article distributed under the terms and conditions of the Creative Commons Attribution (CC BY) license (https:/ / creativecommons.org/licenses/by/ $4.0 /)$.

\begin{abstract}
The repair rate is a very important parameter for system maintainability and can be defined as a frequency of successfully performed repair actions on a failed component per unit of time. This paper analyzes the integral characteristics of a stochastic repair rate for corresponding values of availability in a system operating under maintenance contracts. The probability density function (PDF) of the repair rate has been studied extensively and it was concluded that it is not a symmetric function so its mean value does not correspond to its maximum. Based on that, the equation for the envelope line of the PDF maximums of the repair rate has been provided. Namely, instead of repair rate PDF equations, we can use envelope line parameters for certain calculations, which are expressed in a simpler mathematical form. That will reduce time required for calculations and prediction and enhance reactions in failure events. Further, for the analytical and numerical evaluation of a system performance, the annual repair rate PDFs are analyzed, such as particular solutions of corresponding differential equation, while the existence of a singular solution is considered and analyzed under different conditions. Moreover, we derived optimal values of availability for which the PDF maximums have been obtained. Finally, in order to generalize the behavior of the repair process, a partial differential equation, as a function of the repair rate process and availability parameter, has been formed.
\end{abstract}

Keywords: repair rate; dynamic characteristic; maintenance contracts

\section{Introduction}

The maintenance contracts are of particular interest to the defense and air force industry, which desires to reduce the overall operating costs of maintaining a complex system with simultaneous improvement of its performance [1,2]. The major criteria for signing of these contracts are availability [3], number of spare parts and reliability. Kang et al. have examined the systems for supplies management according to the maintenance contracts in detail [4]. The methodology that they have developed helps in determining the system's availability based on the reliability of its components and possibilities for their maintenance. In their research, they concluded that the mean time between failure (MTBF) and the mean time to repair (MTTR) have the greatest impact on availability. Papers [5-8] provided a major contribution concerning the issue of determining the availability of repairable systems and components under the maintenance contracts. In [9], this problem was examined with the implementation of several assumptions, such as fixed frequency of failures, fixed time required to repair those failures and unlimited capacities required for repairs. Based on that, the authors concluded that service at maintenance and repair 
organization (MRO) should be as short and as cost-effective as possible. Some interesting results regarding the minimal repair rate are given in $[10,11]$. Actually, according to [12], repair data are often used to predict the repair time or maintainability performance of an item. Time series can also be used for modeling services at MRO. For instance, ARMA models presented in $[13,14]$ can be adapted for this purpose. Further, in $[15,16]$, models for analysis of repair time were presented. Due to importance of the repair time in MRO, in [17], the authors have recommended a novel stochastic model for determining the annual repair rate for critical aircraft components in order to achieve the desired level of availability. Those results can be used for the planning of the required numbers of spare parts and the repair facilities' overall capacities. The described model can also be used to assess other vital parameters related to system maintenance. Moreover, setting the availability parameters to the required values and assuming that the basic level of supplies is fixed to a constant value, a repair rate can be determined not only for critical components presented in the paper, but any other system that can be repaired and fulfills the previously set assumptions. Using an expression for the probability density function (PDF) can precisely model the repair rate by generating the exact values of repair rate samples for the related values of availability and the MTBF. Such simulations can also serve for dynamic forecasting of system's characteristics, as well as for planning and implementation of new repair stations and increase in any other repair capacities in order to improve efficiency of the maintenance systems. The previous analysis of those probabilistic models for describing the repair process, depending on the individual relevant parameters for specific availability conditions, resulted in the idea to focus the subject of research at the request of the integral description of phenomena that affect the complex system renewal process. To the best of the authors knowledge, no study that investigates the integral characteristics of the repair process under maintenance contracts has been presented in the literature so far. We tried to determine the analytical expressions required to describe the boundary conditions that could be useful in planning of the repair process.

This paper is structured in the following way: In Section 2, we discuss the preliminaries about the random repair process. The integral characteristics of the repair rate function is presented in Section 3. In this section, we have provided an equation of an envelope curve of repair rate maximums. Moreover, by observing this envelope equation as a singular solution, we have derived a differential equation that can describe the dynamics of this repair process, where the repair rate PDFs denote the particle solutions of such differential equation. Further, we have derived the optimal values of availability for which the PDF maximums have been obtained. The results obtained in this section are graphically presented and analyzed in the function of system parameters in Section 4. This section includes yet another contribution by this paper-a partial differential equation as a function of the repair rate and availability. Finally, the concluding remarks are outlined in Section 5.

\section{Repair Rate Model}

With regard to the system maintenance, the repairable and non-repairable systems should be clearly distinguished. In this paper, we deal exclusively with the repairable systems. The repairable systems are those that can be restored to their operational state after the failure. The system can only exist in one of the two states i.e., it alternates between operative and non-operative state. The sequence of operational time of the system can be denoted by $U=\left(U_{1}, U_{2}, \ldots, U_{n}\right)$, while the failure states can be denoted by $D=\left(D_{1}, D_{2}, \ldots, D_{n}\right)$. We have assumed that $W=\left(\left(U_{1}, D_{1}\right),\left(U_{2}, D_{2}\right), \ldots,\left(U_{n}, D_{n}\right)\right)$ is a set of independent alternating cycles. We have also assumed that the perfect repair had been carried out at the constant rate after which system behaved exactly the same as the new one. The renewal process corresponding to this model is called the alternating renewal process. Since $E(U)$ is actually MTBF and $E(D)$ is MTTR, based on the renewal theorem [18] we can determine the system's availability as:

$$
A=\frac{E(U)}{E(U)+E(D)}
$$


which is, based on the previous, equal to:

$$
A=\frac{M T B F}{M T B F+M T T R} .
$$

In [17], the authors observed such system-a system with an alternating renewal process, which, after repairs, returns to its original state and they determined the annual repair rate in the case when the MTBF has a Rayleigh distribution i.e.,:

$$
M T B F=\int_{0}^{\infty} t p_{T}(t)=\int_{0}^{\infty} \frac{2 t^{2}}{x} \exp \left(-\frac{t^{2}}{x}\right) d t,
$$

given with:

$$
p_{T}(t)=\frac{2 t}{x} \exp \left(-\frac{t^{2}}{x}\right)
$$

where $x$ is the distribution parameter determined by the relation $x=\frac{4(M T B F)^{2}}{\pi}$. Based on these assumptions the authors determined the PDF function of the repair rate $\mu$ as

$$
p_{\mu}(\mu)=\frac{8 A^{2}}{(1-A)^{2} \mu^{3} \pi x_{0}} \exp \left(\frac{-4 A^{2}}{(1-A)^{2} \mu^{2} \pi x_{0}}\right)
$$

where $x_{0}=E(x)$ i.e., expected value of $x$ for the observed part of the failed system. As shown in [6], this PDF is not symmetric so its mean value does not correspond to its maximal value. Since this value is an important performance indicator of a repair process under maintenance contracts, it would be interesting to observe the behavior of its maximum value.

Here, we will observe this PDF as a function of two parameters: the repair rate, $\mu$ and the availability, $A$, while $x_{0}$ from Equation (5) will be observed as a constant, with its value related to the MTBF. In order to determine and analyze the integral characteristics of repair rate distribution, one of the PDF parameters is treated as a variable. The other parameters are observed as constant values. This process produces the PDF family of curves. Further, we analyze, analytically and numerically, the position of the PDF curves family maximums. The analytical analysis is performed by using the first derivative of the observed function. Further, the equation of the envelope of the curves maximum is considered. The analytical and numerical solution for direction coefficients and values on ordinate-axis are provided. The dynamics of the repair rate process are described by obtained differential equation where the PDF family of curves is a singular solution of this equation while PDFs are its particular solutions.

\section{Integral Characteristics of Repair Process}

In this paper, in order to verify some of the obtained results, an unmanned aerial vehicle (UAV) has been observed. The UAV is comprised of three main components: engine, propeller and avionics. It has been utilized mostly for military purposes while in civil sector its use was limited due to the insufficient reliability date [19]. Mirzahosseinian and Piplani [17] studied the UAV's maintenance under maintenance contracts, which assures the predetermined level of system availability. They calculated that UAV's engine failure rate is $\lambda=1.92$. Further, these authors concluded that the repair efficiency needs to be improved in order to achieve the desired availability. Due to that fact, Kontrec et al. in [17] observed the repair rate as a stochastic process and the engine repair time was calculated on annual basis for the availability values set as:

$$
A=0.85, A=0.90, A=0.95 \text {. }
$$

The graphic presentation of the dependence of the PDF of engine's repair rate versus the repair rate, for a fixed value of the MTBF parameter $x_{0}$ and different values of availabil- 
ity parameter $A$, in logarithmic scale, is shown in Figure 1 . The analysis of this dependence shows that the increase in parameter $A$ results in smaller values of the PDF maximums reached for higher values of repair rate. It is obvious from Figure 1 that there is an envelope of the family of curves, which excludes the possibility that for some value of the variable, the PDF has a higher value than the envelope function for that same value.

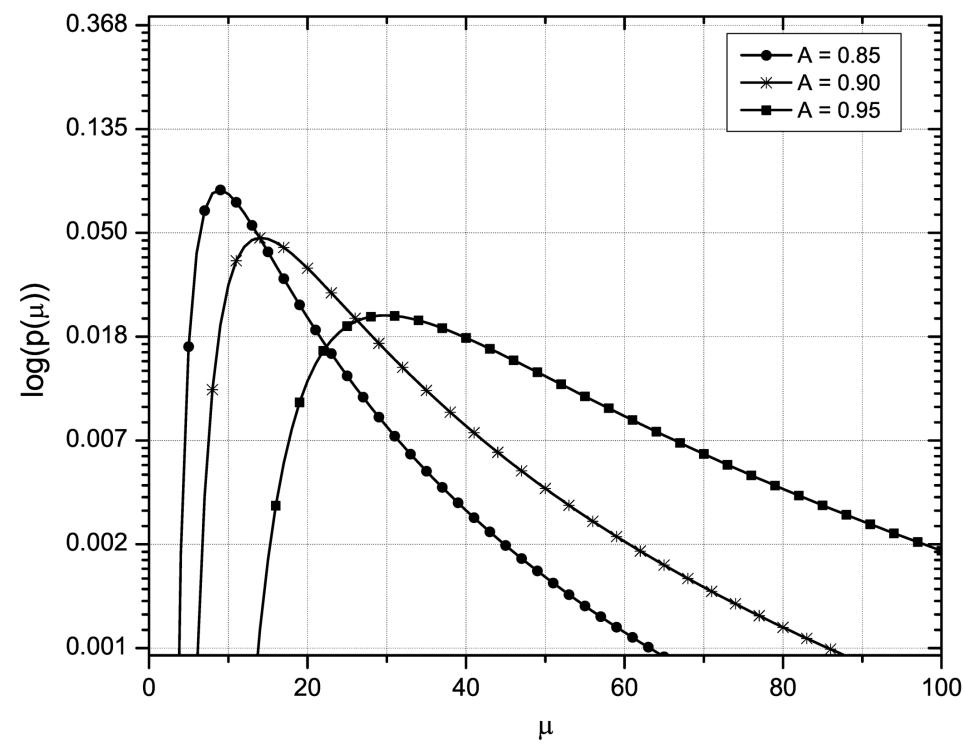

Figure 1. PDF of engine repair rate.

In this paper, we observe the boundary conditions. It can be noticed that all the maximums lie along a single curve. The envelope of a family of curves of the PDF function is also a curve that represents the boundary beyond which there are no curves of that family, and it is also tangent to each curve from the family at the point of its maximum. The envelope does not belong to the family of curves whose envelope it is, so it is important to determine its equation from that aspect as well. Further, the envelope of maximums is traceable. In order to determine the values of the repair rate level when the maximums are reached, as well as the values of maximums and a direction coefficient of the repair rate, the first derivative of the relative repair rate level is determined.

$$
\begin{aligned}
& \left.\frac{d p_{\mu}(\mu)}{d \mu}\right|_{\mu=\mu_{\max }}=0 \\
& \mu_{\max }=\frac{2 \sqrt{2} A}{\sqrt{3 \pi x_{0}(1-A)^{2}}} .
\end{aligned}
$$

substituting the above obtained equation of the maximum repair rate into (5), yields:

$$
p_{\mu_{\max }}(A)=3 \sqrt{\frac{3 \pi x_{0}}{8}} \exp \left(-\frac{3}{2}\right) \frac{1}{A}-3 \sqrt{\frac{3 \pi x_{0}}{8}} \exp \left(-\frac{3}{2}\right) .
$$

after calculations, this equation can be further simplified and presented as:

$$
p_{\mu_{\max }}(A) \approx 0.72 \sqrt{x_{0}} \frac{1}{A}-0.72 \sqrt{x_{0}}
$$


or, when we introduce substitution $\tilde{A}=\frac{1}{A}$, it transforms into:

$$
\begin{aligned}
& p_{\mu_{\max }}(\tilde{A})=0.72 \sqrt{x_{0}} \tilde{A}-0.72 \sqrt{x_{0}}=k \tilde{A}+n \\
& \tilde{A}=\frac{1}{A}
\end{aligned}
$$

where $k$ is a direction coefficient of the envelope line while $n$ is value on ordinate axis.

$$
\begin{aligned}
& k=k\left(x_{0}\right)=0.72 \sqrt{x_{0}}, \\
& n=n\left(x_{0}\right)=-0.72 \sqrt{x_{0}} .
\end{aligned}
$$

The envelope determines a certain singular solution of a differential equation, which can describe the dynamics of this process, while the PDF is its particular solution [20]. By applying mathematical procedure explained in [21] (Equation (10)), we can form differential equation. So, first, we determine $\frac{d p_{\mu(\mu)}}{d \mu}$ as:

$$
\frac{d p_{\mu}(\mu)}{d \mu}=\frac{8 A^{2}}{(1-A)^{2} \pi x_{0}} \exp \left(\frac{-4 A^{2}}{(1-A)^{2} \mu^{2} \pi x_{0}}\right) *\left(\frac{-3}{\mu^{4}}+\frac{8 A^{2}}{(1-A)^{2} \pi x_{0} \mu^{6}}\right) .
$$

it is obvious form Equations (5) and (11) that

$$
\frac{8 A^{2}}{(1-A)^{2} \pi x_{0}} \exp \left(\frac{-4 A^{2}}{(1-A)^{2} \mu^{2} \pi x_{0}}\right)=p_{\mu}(\mu) \mu^{3} .
$$

further, by substituting (12) into (11), we can determined singular solution:

$$
\frac{\partial p_{\mu}(\mu)}{\partial \mu}+p_{\mu}(\mu)\left(\frac{3}{\mu}-\frac{8 A^{2}}{(1-A)^{2} \mu^{3} \pi x_{0}}\right)=0 .
$$

According to the theory of differential equations, the singular solutions cannot be derived from general ones, and that is their significance, as well as the significance of the contribution of this paper. Using the obtained differential equations, we are able to simplify the calculations related to determining the characteristics of the repair rate PDF distribution model. Namely, the PDF repair rate distribution functions can, instead of initial equations, be replaced in certain calculations by envelope parameters, which, as shown, are described by simpler functions. This will reduce the time required for numerical calculations and optimize appropriate system failure support. Now, in a similar manner we can determine the values of the availability for which maximum of the PDF are obtained as:

$$
\begin{gathered}
\left.\frac{d p_{\mu}(\mu)}{d A}\right|_{A=A_{\max }}=0 ; \\
A_{\max }=\frac{\mu \sqrt{\pi} \sqrt{x_{0}}}{2+\mu \sqrt{\pi} \sqrt{x_{0}}}
\end{gathered}
$$

The values of these maximums and coefficients of directions of envelope of maximums can be determined as in the previous case.

\section{Result Analysis and Discussion}

The envelopes of the PDF curves families maximums, for different values of the MTBF parameter $x_{0}$, for case where the observed availability is viewed as a parameter, are presented in Figures 2 and 3. 


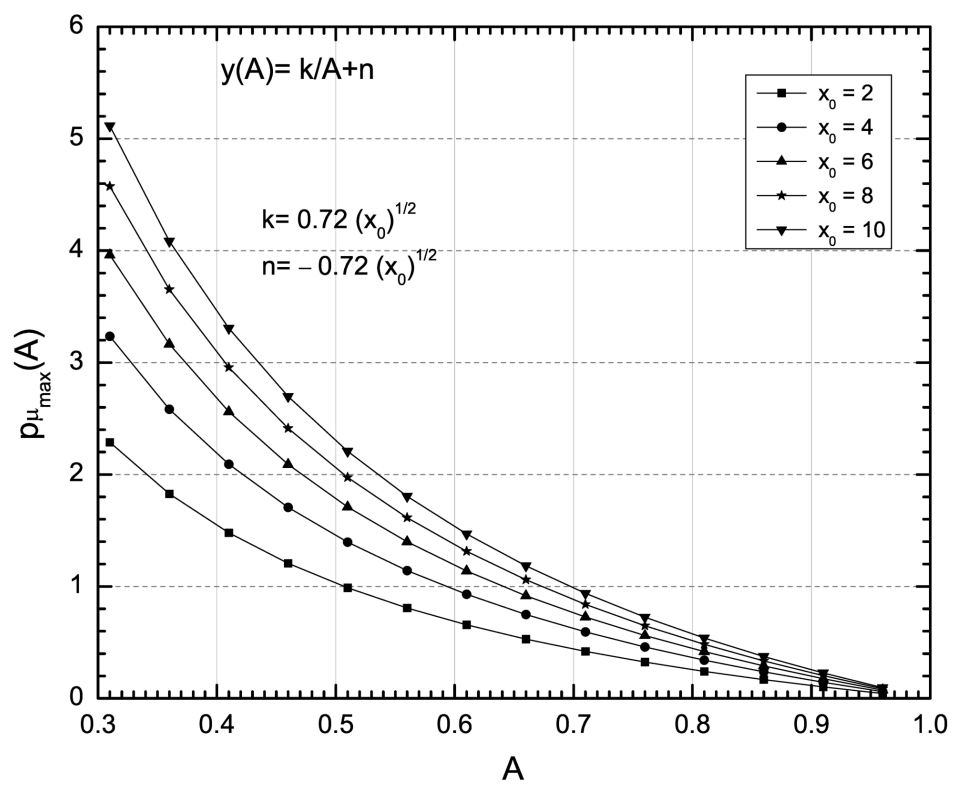

Figure 2. Maximums of the repair rate PDF as a function of required part availability.

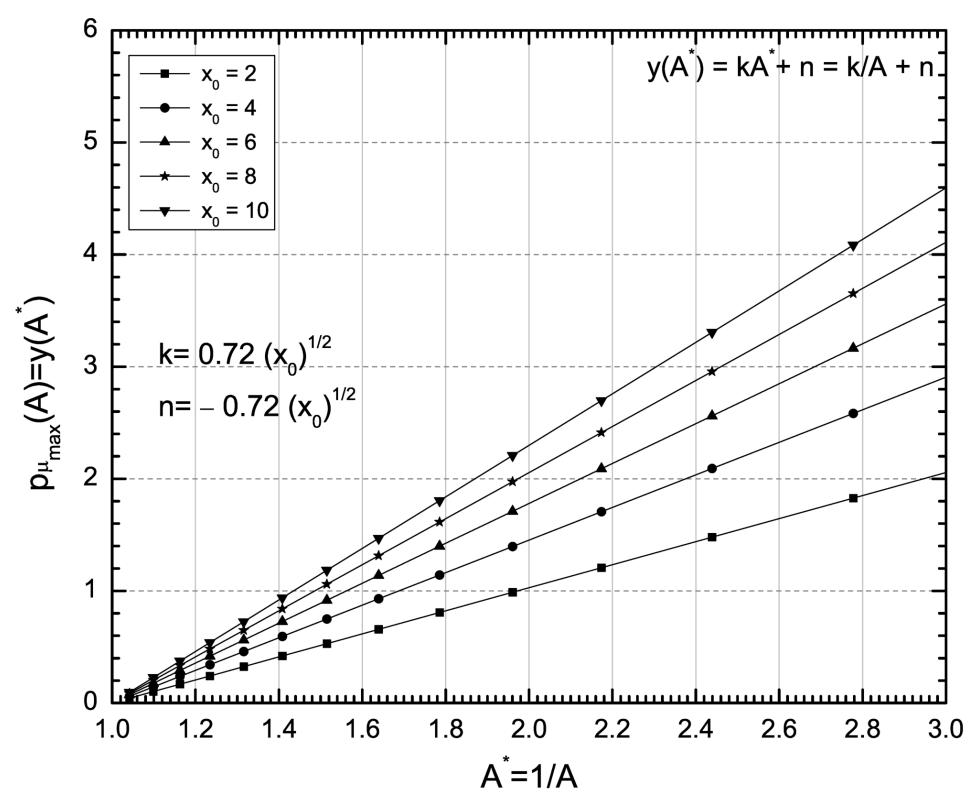

Figure 3. Linearized function of maximums of the repair rate PDF.

In that way, the maximal value of the repair rate PDF can be efficiently predicted. Thus, the boundary conditions for the repair service under maintenance contract, with the predefined MTBF conditions, could be defined, while some system performance measures could also be evaluated, since they are all related to the repair rate. It can be concluded that an increase in the MTBF $x_{0}$ parameter results in increase in the repair rate maximum envelope direction coefficient and decrease in its value on the ordinate axis, when the repair rate PDF curves maximums are analyzed versus parameter $x_{0}$, as it is presented in Figure 2 . Further, it is interesting to observe the linearized form of the repair rate maximum envelope for the observed argument of parameter $\frac{1}{A}$, which is presented in Figure 3. Based on the aforementioned, by taking into account the influence of both the repair rate process and the availability parameter, after providing some basic mathematical transformations, the 
aircraft's engine repair process can be described with the following particular differential equation of first order:

$$
\mu \frac{\partial p}{\partial \mu}+A(1-A) \frac{\partial p}{\partial A}=-\frac{8 A^{2}}{(1-A)^{2} \pi x_{0} \mu^{3}} \exp \left(-\frac{4 A^{2}}{(1-A)^{2} \mu^{2} \pi x_{0}}\right)
$$

where $p=p_{\mu}(\mu)$. By using this expression, these system variables can be expressed dynamically as a differential equation for the unknown repair rate of an aircraft part as a function of availability. More generally, this equation represents the law of repair rate variation of the engine repair process. Figure 4 is a graphical presentation of the partial differential equation solution for the observed engine repair process.

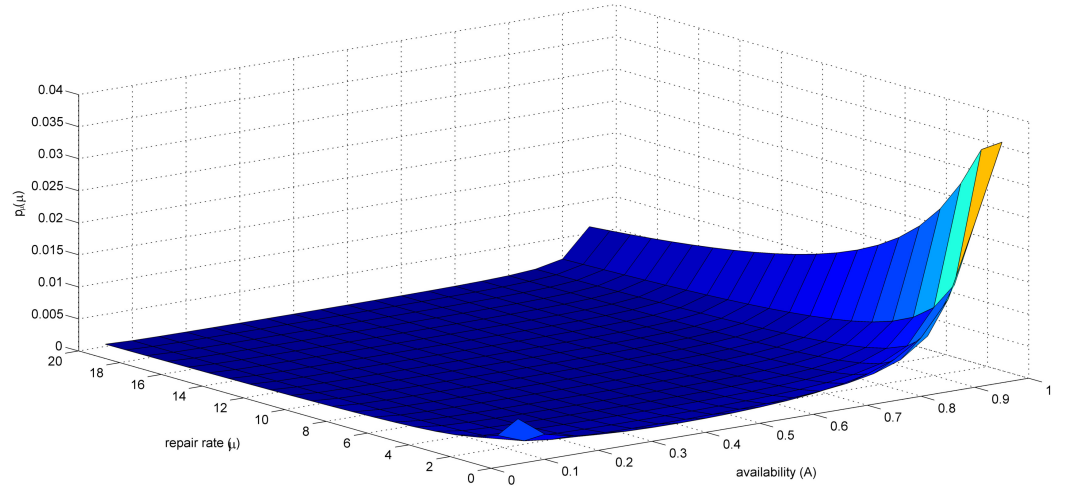

Figure 4. Solution for partial differential equation of engine's repair process.

As stated earlier, the availability of the system operating under maintenance contracts depends on system failure rate, reliability and the repair rate efficiency, which means that repair time should be as short as possible. In the mentioned literature, most of these parameters have been analyzed. In [17] the PDF of a repair has been calculated in order to help maintenance decision-making but in this paper we go further by analyzing its boundary conditions. One of the contributions of this paper is the equation for envelope line of the PDF repair rate maximums. The obtained expression is simpler in mathematical form than the expression for repair rate PDF. This will speed up and simplify the decision making process while planning maintenance activities in regards to demanded availability level. Further, another major contribution here is the partial differential equation which described the repair process and can be used in analysis of the renewal characteristics of the observed system.

\section{Conclusions}

The integral characteristics of a repair process for corresponding availability have been analyzed. By observing the repair rate PDF curve, we have concluded that all the maximums lie along a single curve, and that envelope of maximums is traceable. In that way, the most common value of system repair rate can be efficiently predicted for any state of system parameters; therefore, the boundary conditions for the repair rate process with given availability conditions could be defined, while some other performance measures could also be evaluated, since they are all related to the repair rate PDF. In addition, we have derived the optimal values of availability for which the PDF maximums have been obtained. Finally, in order to generalize the behavior of the aircraft parts' repair rate process, a novel form of partial differential equation as a function of the repair rate and availability has been presented. Analytical considerations of repair rate PDF as particular solutions of provided partial differential equation provides the existence of singular partial differential equation solution, which could be used during the analysis of system renewal characteristics. 
Author Contributions: Conceptualization, N.K. and S.P.; methodology, N.K., J.V. and M.T.; validation, S.P., B.P. and N.K.; writing-original draft preparation, N.K. and J.V.; writing-review and editing, M.T., B.P. and S.P.; visualization, N.K.; supervision, S.P. and J.V. All authors have read and agreed to the published version of the manuscript.

Funding: This research received no external funding.

Institutional Review Board Statement: Not applicable.

Informed Consent Statement: Not applicable.

Data Availability Statement: Not applicable.

Conflicts of Interest: The authors declare no conflict of interest.

\section{References}

1. Phillips, E. Performance based logistics: A whole new approach. Aviat. Week Space Technol. 2005, 163, 52-55.

2. Randall, W.; Pohlen, T.; Hanna, J. Evolving a theory of performance-based logistics using insights from service dominant logic. J. Bus. Logist. 2010, 31, 35-61. [CrossRef]

3. Wong, H.; Cattrysse, D.; Oudheusden, D.V. Stocking decisions for repairable spare parts pooling in a multi-hub system. Int. J. Prod. Econ. 2005, 93, 309-317. [CrossRef]

4. Kang, K.; Doerr, K.; Boudreau, M.; Apte, U. A Decision Support Model for Valuing Proposed Improvements in Component Reliability; Technical Report; Working Paper; Naval Postgraduate School: Monterey, CA, USA, 2005.

5. Mirzahosseinian, H.; Piplani, R. A study of repairable parts inventory system operating under performance-based contract. Eur. J. Oper. Res. 2011, 214, 256-261. [CrossRef]

6. Nowicki, D.; Kumar, U.; Steudel, H.; Verma, D. Spares provisioning under performance-based logistics contract: Profit-centric approach. J. Oper. Res. Soc. 2008, 59, 342-352. [CrossRef]

7. Carpitella, S.; Certa, A.; Izquierdo, J.; La Fata, C.M. k-out-of-n systems: An exact formula for the stationary availability and multiobjective configuration design based on mathematical programming and TOPSIS. J. Comput. Appl. Math. 2018, 330, 1007-1015. [CrossRef]

8. Jeang, A.; Ko, C.; Chung, C.; Chen, Y.; Lin, I. Optimal availability for determining choice and repair policy of system components. Int. J. Qual. Reliab. Manag. 2018, 36, 347-357. [CrossRef]

9. Pogacnik, B.; Duhovnik, J.; Tavcar, J. Aircraft fault forecasting at maintenance service on the basis of historic data and aircraft parameters. Eksploat. I Niezawodn. 2017, 19, 624-633. [CrossRef]

10. Park, M.; Jung, K.; Park, D. Optimal maintenance strategy under renewable warranty with repair time threshold. Appl. Math. Model. 2017, 43, 498-508. [CrossRef]

11. Cha, J.H.; Finkelstein, M. New failure and minimal repair processes for repairable systems in a random environment. Appl. Stoch Model. Bus. Ind. 2019, 35, 522-536. [CrossRef]

12. Ayele, Y.Z.; Barabadi, A.; Fuqing, Y. Mixture Lognormal Cox Regression Repair Model for Prediction of the Repair Time. In Proceedings of the 2018 IEEE International Conference on Industrial Engineering and Engineering Management (IEEM), Bangkok, Thailand, 16-19 December 2018.

13. Stojanovic, V.; Kevkic, T.; Ljajko, E.; Jelic, G. Noise-Indicator ARMA Model with Application in Fitting Physically-Based Time Series. UPB Sci. Bull.-Ser. A Appl. Math. Phys. 2018, 81, 257-264.

14. Randjelovic, M.; Stojanovic, V.; Kevkic, T. Noise-indicator autoregressive conditional heteroskedastic process with application in modeling actual time series. UPB Sci. Bull.-Ser. A Appl. Math. Phys. 2019, 81, 77-84.

15. Kontrec, N.; Panic, S.; Petrovic, M.; Milosevic, H. A Stochastic Model for Achieving Required Level of Availability Based on the Repair Rate Analysis. Teh. Vjesn. 2019, 26, 1171-1175. [CrossRef]

16. Kontrec, N.; Panic, S.; Panic, B.; Markovic, A.; Stosovic, D. Mathematical Approach for System Repair Rate Analysis Used in Maintenance Decision Making. Axioms 2021, 10, 96. [CrossRef]

17. Kontrec, N.; Panic, S.; Petrovic, M.; Milosevic, H. A stochastic model for estimation of repair rate for system operating under performance based logistics. Eksploat. I Niezawodn. 2018, 20, 68-72. [CrossRef]

18. Ross, S. Applied Probability Models with Optimization Applications; Courier Corporation: North Chelmsford, MA, USA, 2013.

19. Krawczyk, M. Conditions for Unmanned Aircraft Reliability Determination. Eksploat. I Niezawodn. 2013, 15, 31-36.

20. Moussiaux, A.; Polyanin, V.Z.; Zaitsev, V.F. Handbook of First Order Partial Differential Equations; Taylor \& Francis: London, UK, 2002.

21. Stefanovic, H.Z.; Milic, D.; Stefanovic, D.; Milosavljevic, S. Some integral characteristics of MRC receiver in Nakagami-m fading environment. Int. J. Reason.-Based Intell. Syst. 2013, 5, 183. [CrossRef] 